\title{
Jigless knotless internal brace versus other open Achilles tendon repairs using a progressive rehabilitation protocol: a biomechanical study
}

\author{
Po-Yen Ko ${ }^{1,2}$, Chieh-Hsiang Hsu' ${ }^{1}$, Chih-Kai Hong ${ }^{2}$, Ming-Tung Hung ${ }^{4}$, Wei-Ren Su², Po-Ting Wu ${ }^{1,2}$, \\ I-Ming Jou $3,4^{*+}$ and Fong-Chin Su ${ }^{1 *+}$
}

\begin{abstract}
Background: The jigless knotless internal brace surgery (JKIB), a modified minimal invasive surgery (MIS) for acute Achilles tendon injury, has advantages of preventing sural-nerve injury in MIS and superficial wound infection in open surgery, as demonstrated in previous clinical research. However, to date, biomechanical testing has not yet been validated.

Materials and methods: Sixty fresh porcine Achilles tendons were used to compare the JKIB with other open surgery techniques, the four-stranded Krackow suture (4sK) and the triple-bundle suture (TBS) in biomechanical testing with cyclic loading set at $1 \mathrm{~Hz}$. This approach simulated a progressive rehabilitation protocol where $20-100 \mathrm{~N}$ was applied in the first 1000 cycles, followed by $20-190 \mathrm{~N}$ in the second 1000 cycles, and then $20-369 \mathrm{~N}$ in the third 1000 cycles. The cycles leading to repair gaps of $2 \mathrm{~mm}, 5 \mathrm{~mm}$, and $10 \mathrm{~mm}$ were recorded. The survival cycles were defined as repair gap of $10 \mathrm{~mm}$.

Results: With respect to survival cycles, a significant difference was found among the three groups, in which the TBS was the most robust, followed by the JKIB and the 4sK, where the mean survived cycles were $2639.3+/-263.55$, $2073.6+/-319.92$, and $1425.25+/-268.96$, respectively. Significant differences were verified via a post hoc analysis with the Mann-Whitney $\mathrm{U}$ test after the Bonferroni correction $(p<0.017)$.

Conclusions: The TBS was the strongest suture structure in acute Achilles tendon repair. However, the JKIB could be an option in acute Achilles tendon repair with the MIS technique due to it being more robust than the 4sK, which has been typically favored for use in open repair.
\end{abstract}

Keywords: Achilles tendon rupture, Minimally invasive, Jigless knotless internal brace, Biomechanical study, Krachow suture, tipple bundle

*Correspondence: jming@mail.ncku.edu.tw; fcsu@ncku.edu.tw

†-Ming Jou and Fong-Chin Su contributed equally to this work.

${ }^{1}$ Department of Biomedical Engineering, National Cheng Kung

University, Tainan, Taiwan

${ }^{4}$ GEG Orthopedic Clinic, Tainan, Taiwan

Full list of author information is available at the end of the article

\section{Introduction}

Many surgeons debate about the best management of acute Achilles tendon tears since it is a frequently ruptured major tendon with high incidence in middleaged men that typically occurs during recreational sports [1-5]. For active young athletes, surgical repair of ruptured Achilles tendon is benefited by early ankle mobilization, which leads to improved outcomes due to better muscular tendinous tropism, good collagen original author(s) and the source, provide a link to the Creative Commons licence, and indicate if changes were made. The images or other third party material in this article are included in the article's Creative Commons licence, unless indicated otherwise in a credit line to the material. If material is not included in the article's Creative Commons licence and your intended use is not permitted by statutory regulation or exceeds the permitted use, you will need to obtain permission directly from the copyright holder. To view a copy of this licence, visit http://creativecommons.org/licenses/by/4.0/. The Creative Commons Public Domain Dedication waiver (http://creativecommons.org/publicdomain/zero/1.0/) applies to the data made available in this article, unless otherwise stated in a credit line to the data. 
alignment, and preventing scar adhesions and muscle atrophy [6-9].

There are several operative options for Achilles repairs, including open repair with or without augmentation, percutaneous repair, and minimally invasive surgery (MIS) [10-12]. When comparing the outcome between MIS and open surgery, no significant differences have been noted in the rate of re-rupture, deep infection, tissue adhesion, or nerve injury based on the results of one high-quality meta-analysis [13]. However, MIS has been reported as leading to better subjective outcomes, improved cosmetic appearance, and a significantly lower rate of superficial infection and wound healing complications [13]. Although a number of MIS methods have been developed, recent efforts have advanced the technique of the mini-open or MIS methods [14-25]. Kakiuchi et al. were the first to describe a combination of the mini-open and the percutaneous techniques over two decades ago [21]. Kakiuchi's method has since been modified in several ways, and now commercial repair tools are available that make it possible for surgeons to easily perform MIS [14, 16, 19, 25]. However, an increased risk of iatrogenic sural nerve injuries in mini-open or MIS techniques has been reported [18, 23, 26-30].

According to a cadaver study, surgeons can decrease the risk of iatrogenic sural nerve injury by conducting all percutaneous suturing within $8 \mathrm{~cm}$ proximal to the calcaneal tuberosity [31]. The aforementioned study reported that the Achilles tendon lateral border crossing site of the sural nerve is approximately $8-$ to $10-\mathrm{cm}$ above the calcaneus tuberosity, in most cases [31]. In response, the "jigless knotless internal brace technique" (JKIB) was developed, which can be perform in a minimally invasive fashion without the risk of iatrogenic superficial sural nerve injury [22]. Although good clinical outcomes in a case series were noted, the suture strength has not yet been validated. Accordingly, we chose the four-stranded Krackow suture (4sK) for comparison since this suture is favored for open repair due to the fact that it is easily performed and has obtained good clinical outcomes based on results given in previous publications [32]. In addition, we chose the triple-bundle technique (TBS) as another suture for comparison because it was shown to be stronger than the 4sK suture in a biomechanical study [33]. The current study was aimed toward a biomechanical comparison of the JKIB with other open-repair techniques applied during a simulated progressive rehabilitation program. We hypothesized that the biomechanical strength of the JKIB was not less than other openrepair techniques applied in this study.

\section{Materials and methods}

\section{Sample collection and preparation}

Sixty fresh porcine Achilles tendons were acquired from fresh adult male pigs (2 years in mean age). The pigs were obtained from a local slaughterhouse according to.

Taiwan national bureau of animal and plant health inspection and quarantine, council of agriculture regulation No. 0007. All specimens were stored in a $-20^{\circ} \mathrm{C}$ freezer on the way from the local slaughterhouse to the laboratory then thawed to room temperature immediately for experimental assessments. To prevent desiccation, all samples were wrapped in saline-soaked gauze when thawing. The samples were then divided evenly into three surgical technique groups: (1) the four-stranded Krackow (4sK) suture end-to-end open repair $\left(\mathrm{Hi}-\mathrm{Fi}^{\circledR}\right.$ Suture Conmed) (Fig. 1A); (2) the triple-bundle suture technique (TBS) ( $\mathrm{Hi}-\mathrm{Fi}^{\circledR}$ Suture Conmed) (Fig. 1B), and (3) the jigless knotless internal brace technique (JKIB) (PopLok ${ }^{\circledR}$ Knotless Suture Anchors; Hi-Fi ${ }^{\circledR}$ Suture CONMED) (Fig. 1C).

\section{Surgical procedure}

All surgical procedures for all specimens were carried out by an orthopedic foot and ankle surgeon (PYK). An Achilles tendon rupture was created using a No. 10 scalpel running the section perpendicular to the tendon fiber at $4 \mathrm{~cm}$ proximally from the calcaneal insertion center. Details of the surgical procedure are provided below:

(1) The four-stranded Krackow suture (4sK): The Krackow suture was conducted according to Krackow [34]. Three locking loops were placed $5 \mathrm{~mm}$ in each strand and at each end of the tendon with the $\mathrm{Hi}-\mathrm{Fi}^{\circledR}$ Suture (Conmed). A $5 \mathrm{~mm}$ stitch interval was chosen because stitch intervals of $5.0 \mathrm{~mm}$ have been found to have significantly smaller elongation compared with other longer stitch intervals after cyclic loading [35]. The loops were tightened to obtain end-to-end repair after three surgeon's knots were tied (Fig. 1A).

(2) The triple-bundle suture technique (TBS): Each bundle was located in the lateral portion of the tendon and was composed of three cross loops at the proximal end and two cross loops tightened with three surgeon's knots at the distal end. The bundle located in the central portion of the tendon was composed of three cross loops at the distal end and two cross loops tightened with three surgeon's knots at the proximal end. The $\mathrm{Hi}_{-} \mathrm{Fi}^{\circledR}$ Suture (Conmed) was used in the triple-bundle suture technique (Fig. 1B). 
A

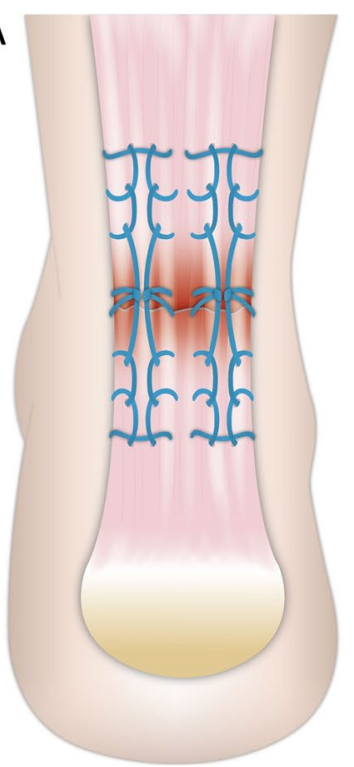

B

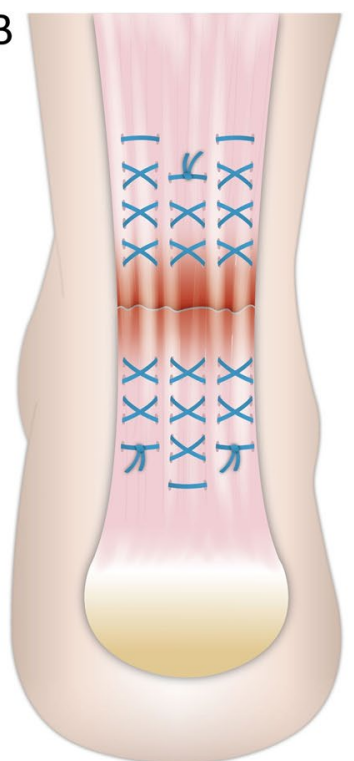

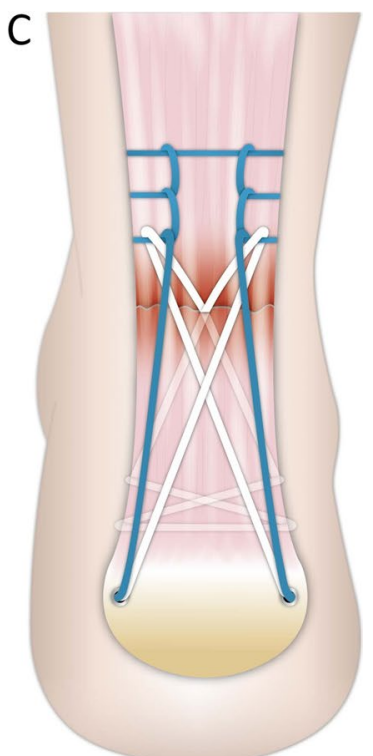

Fig. 1 Schematic diagram of the four-stranded Krachow suture repair (4sK) (A), triple bundle suture technique (TBS) (B), and the jigless knotless internal brace technique (JKIB) (C). The blue line and white line in A, B, and C represent the Hi-Fi ${ }^{\circledR}$ Suture (Conmed); the symbol " $\boldsymbol{\bullet}^{\prime \prime}$ in $\mathbf{C}$ is the $4.5 \mathrm{~mm}$ PopLok ${ }^{\circledR}$ used as the knotless anchor

(3) The Jigless knotless internal brace technique (JKIB): The JKIB was conducted as in our previous report [22]. Krackow sutures were applied at the proximal stump, as described above. The percutaneous suture with the $\mathrm{Hi}-\mathrm{Fi}^{\circledR}$ Suture (Conmed) was crisscrossed through the distal stump. The end of the distal-stump suture was looped through the Krackow locking loop at the proximal stump. The ipsilateral Krackow sutures and the contralateral crisscrossed sutures were seated at the calcaneal tuberosity with two $4.5 \mathrm{~mm}$ PopLok ${ }^{\circledR}$ Knotless Suture Anchors (Conmed) (Fig. 1C).

\section{Biomechanical testing}

Each calcaneus of the repaired Achilles tendon was fixed horizontally in a custom-made adjustable fixture at the base of a dynamic tensile testing machine (MTS Bionix ${ }^{\circledR}$ Servohydraulic Test Systems, Technology Drive Eden Prairie, MN USA) (Fig. 2). The tendon end $3 \mathrm{~cm}$ above of the repair site was rigidly secured by a custom-made steel clamp attached to the testing machine actuator. Each specimen was tested to measure the amount of repair gap occurring at each cyclic load. These data were collected by a hydraulic biomechanical load cell and then transferred with the analog-to-digital data output to a host computer. The cyclic loading protocol and the definition of failure were based on a previous model established by Lee et al. and Demetracopoulos et al. [25,36]. To simulate a progressive rehabilitation program, the tested loading protocol with a total of 3000 cycles at $1 \mathrm{~Hz}$ was composed of three cyclic-loading stages of 1000 cycles each: (1) $20-100 \mathrm{~N},(2) 20-190 \mathrm{~N}$, and (3) $20-369 \mathrm{~N}$. The number of cycles leading to repair gaps of $2-\mathrm{mm}, 5-\mathrm{mm}$, and $10-\mathrm{mm}$ were recorded. The gap was documented during cyclic loading test using a linear variable differential transformer (Parker Hannifin Corporation model S-LVDT-24, range $12.0-\mathrm{mm}$, Williston, VT) (Fig. 2). The tested cyclicloading values represented the force through the tendon during a passive ankle-dorsiflexion stretch $(20-100 \mathrm{~N})$, weight-bearing ambulation with a cam under a 1-in. heel lift shoe $(20-190 \mathrm{~N})$, and without a cam $(20-369 \mathrm{~N})$ [37, 38]. Failure of the repair was defined as a repair gap of over $10 \mathrm{~mm}$. Thus, the survival cycles were defined as the number of cycle leading to a $10 \mathrm{~mm}$ repair gap.

\section{Statistical analysis}

To determine the sample size, a pilot study was performed based on elongations after cyclic loading, for which 15 specimens were randomly assigned to three groups (4sK, TBS, and JKIB). The effect size was calculated as 0.53 after the pilot study. Then, a total specimen number of 60 was determined after $\alpha=0.05$, a power $(1-\beta)$ of 0.80 , and an $f$ value of 0.53 were set under G power, ver. 3.1.3 (http://www.gpower.hhu.de; Heinrich Heine-University of Dusseldorf, Dusseldorf, Germany). All data collected from the biomechanical loading cell, elongation, and failure load were exported to SPSS, 


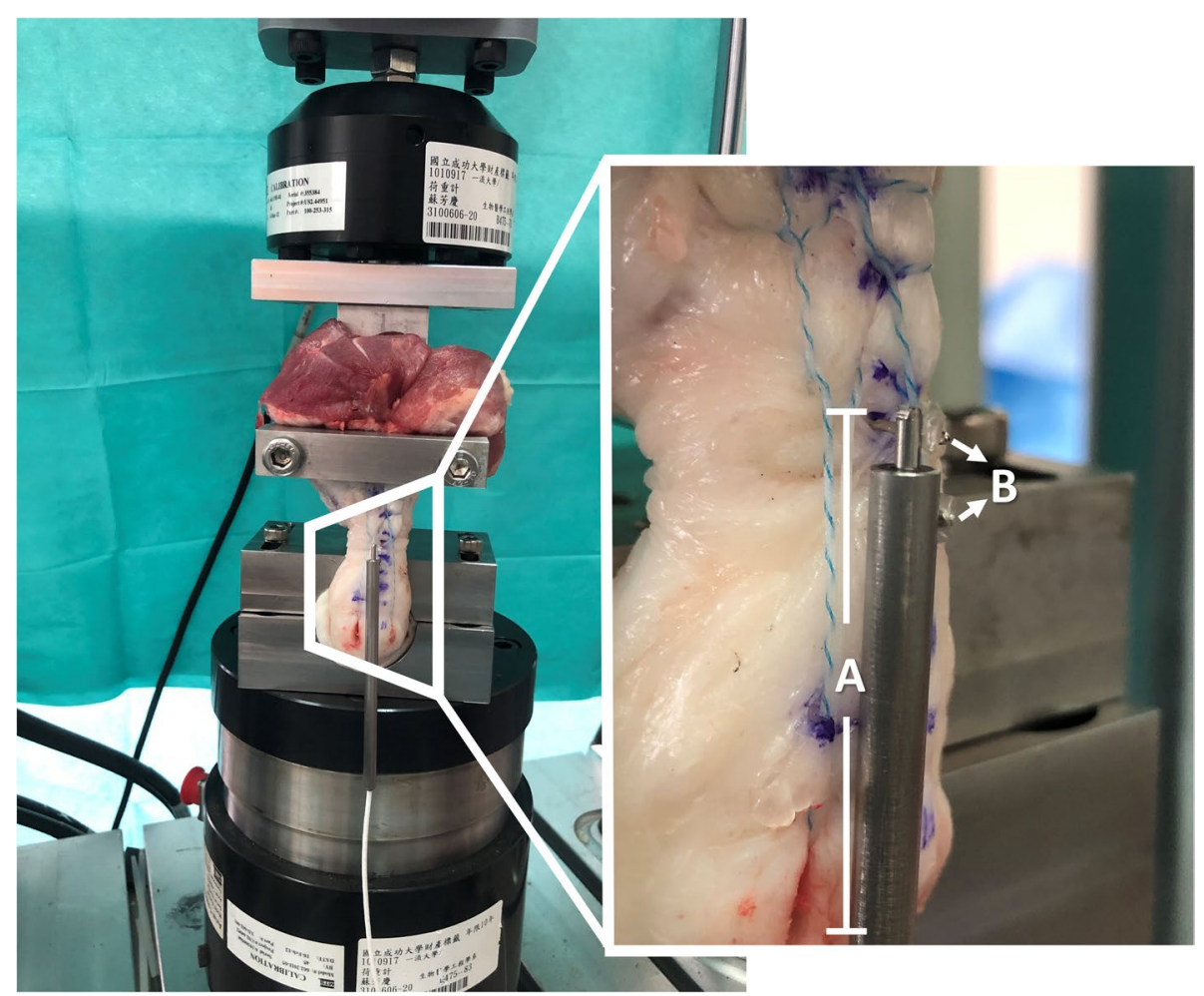

Fig. 2 The repaired Achilles tendon was anatomically oriented and fixed in a dynamic tensile-testing machine. The linear variable differential transformer (LVDT) (A) was used to measure the repair gap created during the cyclic loading test. The LVDT was welded with two pins (B) adjacent to the repair gap, which were used to fix the LVDT onto the specimen

version 17.0 (SPSS Inc., Chicago, IL, USA) for statistical comparisons.

Cycles to the determined repair gap among the three groups were compared using the Kruskal-Wallis test. $p<0.05$ indicated statistical significance. A post hoc analysis was conducted with the Mann-Whitney U-test, where a significance difference was set as $p<0.017$ after the Bonferroni correction.

\section{Results}

\section{Survival cycles}

Survival cycles were defined as a cycles leading to repair gaps of $10-\mathrm{mm}$ in this research. All repairs survived in the first stage and during cyclic loading ranging from 20 to $100 \mathrm{~N}$ during the biomechanical testing, but no repairs survived all three stages of the cyclic loading. There were significant among-group differences in the survival cycles after the post-hoc analysis $(p<0.001)$ (Fig. 3). The mean survived cycles for the $4 \mathrm{sK}$, TBS, and JKIB techniques were $1425.3+/-268.9,2639.3+/-263.6$, and 2073.6 $+/-319.9$, respectively (Fig. 3 ). The median and range of the survived cycles for the 4sK, TBS, and JKIB techniques were 1384.5 (1003-1875), 2712.5 (1901-2953), and 2062.5 (1504-2741), respectively (Fig. 4).

\section{Number of cycles to the repair gap}

Kruskal-Wallis testing showed there were significant differences in the three treatment groups when comparing the measurement (number of cycles to the 2-mm repair gap and 5 -mm repair gap) $(p<0.001)$ (Fig.3). Post hoc testing (Mann-Whitney) revealed that in all measurements, the TBS was most durable, followed by the JKIB and 4 Sk $(p<0.001)$ (Fig.3). Also, the $4 \mathrm{sK}$ was weakest $(p<0.001)$ (Fig.3).

\section{Failure mode}

All failures in the $4 \mathrm{sK}$ group were due to suture breakage. Meanwhile, the failure mechanisms for the TBS group included 14 specimens tearing at the tendon-suture interface and 6 specimens undergoing suture breakage. In the JKIB group, all specimens failed due to tears in the proximal stump tendon-suture interface.

\section{Discussion}

The results of the cyclic loading test showed that the triple-bundle suture technique (TBS) was the strongest suture structure followed by the Jigless knotless internal brace technique (JKIB). The four-stranded Krachow suture $(4 \mathrm{sK})$ was significantly weaker than other two 


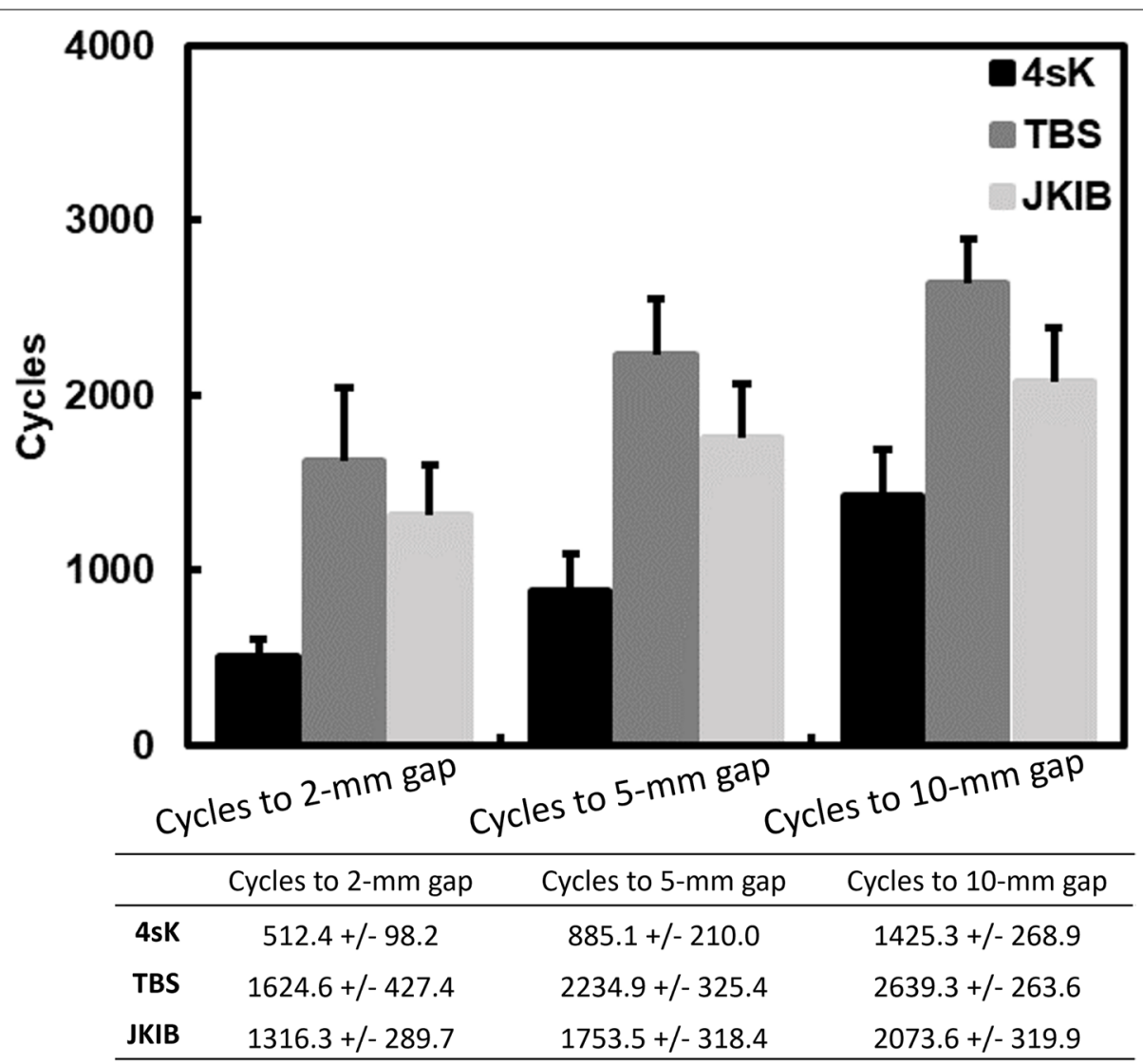

Fig. 3 The cycles to the repair gaps of 2-mm, 5-mm, and 10-mm for the Achilles tendon repair for the four-stranded Krachow suture repair (4sK), triple bundle suture technique (TBS), and jigless knotless internal brace technique (JKIB). Post hoc testing (Mann-Whitney) revealed that the TBS was most durable, followed by the JKIB and 4sK in all measurements $(p<0.001)$. In addition, the JKIB was stronger than 4 sK in all measurements $(p<0.001)$

groups. Of the three groups, the JKIB technique could be performed as a minimally invasive technique and showed good clinical results in a previous study [22].

Although numerous biomechanical studies of Achilles tendon repairs have been published over the past three decades, controversy remains regarding the different suturing techniques [25, 33, 36, 39-43]. In particular, elongation after post-surgical rehabilitation is a concern, and there is also no consensus in terms of suturing technique under the simulated rehabilitation protocols in biomechanical studies [36, 39, 44]. The biomechanical strength of the JKIB, which can be performed in minimally invasive fashion was not validated in previous research [22]. In response, we used animal simulated-progressive rehabilitation protocols to biomechanically study to evaluate the repair strength of the JKIB technique.

Recently, several researchers have made attempts to determine how much Achilles tendon elongation is clinically significant, but there is still no consensus [45-49]. In our research, we defined the failure of the cyclic loading test as a repair gap of $10-\mathrm{mm}$, which was also defined as biomechanical failure in previous research $[25,36]$. In addition, previous research showed that the repair gap over 5 - $\mathrm{mm}$ would lead to weakness in plantar flexion [48, 49]. All specimens survived the $20-100 \mathrm{~N}$ cyclic loading. This result was consistent with those obtained for early ankle passive range of motion exercises after Achilles tendon repair, which was suggested in a recent clinical metaanalysis study $[50,51]$. The results of the present study showed that the JKIB technique was stronger than the $4 \mathrm{sK}$, but there was still felt to be a risk of a failed repair when weight-bearing ambulation with a cam under a 1-in. heel lift shoe was tested since some specimens did not survive the 20-190 N cyclic loading condition.

The greater strength of the JKIB over the $4 \mathrm{sK}$ could be due to differences in suture fixation. The suture fixation used in the JKIB group was a knotless anchor seated over the calcaneus rather than the end-to-end knot used in the $4 \mathrm{sK}$ group. The results were similar to the findings of Clanton et al., who compared the percutaneous Achilles repair system (PARS), and SpeedBridge 


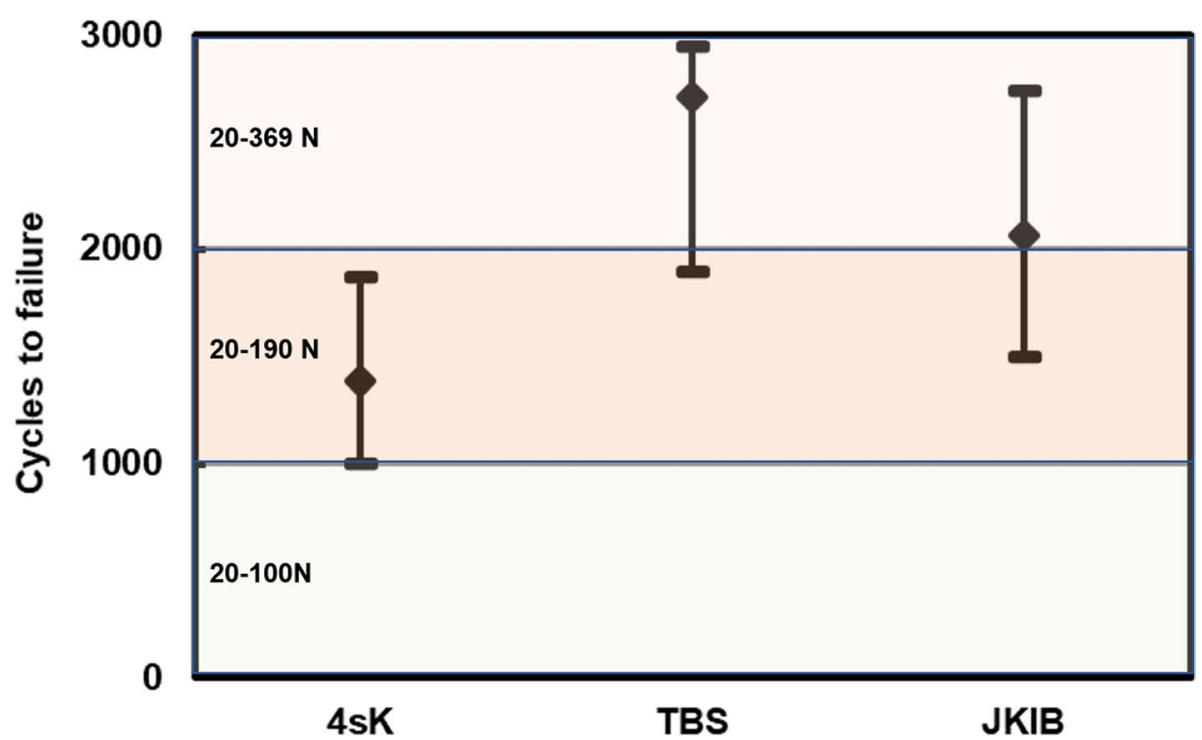

Fig. 4 Median (diamond mark) and range (error bars) for the survival cycles of the three different repair techniques. The loading amount was noted for the three different cyclic loading stages. The means (range) of the four-stranded Krachow suture repair (4sK), triple bundle suture technique (TBS), and jigless knotless internal brace technique (JKIB) were 1384.5 (1003-1875), 2712.5 (1901-2953), and 2062.5 (1504-2741), respectively. There were significant between-group differences in the survival cycles after the post-hoc analysis $(p<0.001)$

(SB) repairs [44]. They found that the SB repair was stronger than the PARS repair in a cyclic loading test. Although the suture configurations were all the same in the proximal stump in PARS and SB, the suture was seated at the calcaneus using a knotless anchor in the $\mathrm{SB}$, while the suture was tied end-to-end in the PARS condition [44]. Furthermore, the present study showed that the JKIB failure mode was a tear in the proximal stump tendon-suture interface with the anchor remaining grossly intact, but all of the $4 \mathrm{sK}$ samples failed in the form of suture breakage. This finding showed that the suture fixation was stronger in the knotless anchor used in the JKIB group.

An additional factor indicating that the JKIB technique was stronger than the $4 \mathrm{sK}$ was the number of strands crossing the repair site. Although there was only a two strand Krachow suture in the proximal stump in the JKIB group, the looped percutaneous suture in the distal stump increased the number of strands crossing the repair site in the JKIB to six. Biomechanically, the number of strands between each group should be constant to made the results valid, but the four strand end-to-end Krachow suture is still the clinical benchmark in Achilles open repair $[6,9,32,39,40]$. Thus, it was still reasonable to select the 4Sk group for the comparison.

There are several limitations in this work. First, as with other biomechanical studies, this study only offered a time-zero biomechanical representation of each Achilles repair technique. Clinically, the rehabilitation program would be more aggressive over time with increased loading during tendon healing.

Second, the study was conducted on porcine Achilles tendons, not on cadaveric tendons; however, porcine tendon has been adopted in numerous biomechanical works to evaluate various tendon repair methods or fixation techniques used in tendon grafts $[35,52]$. We also found a similar trend in our comparisons between the $4 \mathrm{sK}$ and TBS as well as similar survival cycles for the $4 \mathrm{sK}$, as in previous studies $[33,36]$. According to the findings of Jaakkola et al., the load to failure of the TBS was significantly larger than that for the $4 \mathrm{sK}$ [33]. In the present study, we chose cyclic loading as the measure parameter for simulations of the clinical rehabilitation protocol. The TBS was significantly larger than the $4 \mathrm{sK}$ in terms of the number of cycles to the $2-\mathrm{mm}, 5-\mathrm{mm}$, and $10-\mathrm{mm}$ repair gap. Furthermore, Lee et al. performed a cyclic loading test to compare the $4 \mathrm{sK}$ with and without augmentation with epitendinous sutures [36]. They found that all of the $4 \mathrm{sK}$ samples without augmentation survived the 20-100 N cyclic loading, yet none survived for the entire $20-190 \mathrm{~N}$ cyclic loading cycle, which was the same as the results obtained in this study [36].

In the failure model, the results for the JKIB and $4 \mathrm{sK}$ groups in our animal biomechanical model was similar to the results obtained in cadaveric studies performed by Cox et al., Heitman et al., and Huffard et al. [39, $40,53]$. Cox et al. analyzed the mechanical strength of knotted and knotless suture bridge repairs of an 
Achilles tendon insertion. Their result showed that all specimens failed at the tendon-suture interface, which was the same in the failure mode in the JKIB group in this study [53]. Although the suture structure of the JKIB group was different from the suture bridge in an Achilles tendon insertion repair, there were knotless anchors seated in the calcaneus when performing the JKIB or suture bridge. The $4 \mathrm{sK}$ group in the present work primarily failed due to suture breakage, which is comparable to the findings of Heitman et al. and Huffard et al. $[39,40]$. The TBS in the present work tore primarily at the tendon-suture interface, while the findings of Jaakkola et al. showed that most TBS specimens tore at the tendon clamp [33]. The difference in the failure mode in the TBS group may have been due to differences in the biomechanical protocol. Jaakkola et al. performed the load to failure test but not the cyclic loading test. Therefore, we believe the results of the present study to be valid.

In conclusion, the TBS was the strongest suture structure in acute Achilles tendon repair. But, the JKIB technique can be considered another treatment option in acute Achilles-tendon rupture with the MIS technique due to better survival after the cyclic loading test compared with the $4 \mathrm{Sk}$ technique, which is a popular opentype repair. Future studies should compare the gapping after cyclic loading in the JKIB with the proximal Krackow suture fixed at the distal calcaneal using anchors alone without augmented extra sutures at the distal stump. In addition, further clinical research is necessary to validate the results of this biomechanical research.

\section{Acknowledgements}

We are grateful to Ms. I-Wen Shene, and Ms. Ying-Chiu Lin for their excellent assistance with carrying out the study. None of the authors has a commercial interest relevant to the manuscript.

\section{Authors' contributions \\ Conceived and designed the study: PYK, IMJ, FCS. Performed the study: PYK. Analyzed the data: PYK, CHH, CKH, MTH, IMJ, WRS, PTW, FCS. Contributed reagents/materials/analysis tools: CHH, CKH, IMJ, WRS, PTW, FCS. Wrote the manuscript: PYK, IMJ, FCS. All authors have read and approved the manuscript.}

\section{Funding}

This study was supported by grant MOST108-2314-B-006-011-MY2 from the National Science Council, Taiwan, and grant NCKUH-10904016 from the National Cheng Kung University Hospital, Tainan, Taiwan.

\section{Availability of data and materials}

The datasets used during the current study are available from the corresponding author on reasonable request.

\section{Declarations}

Ethics approval and consent to participate Not applicable due to usage of cadaveric porcine Achilles tendon, rather than live animals.

\section{Consent for publication}

Not applicable.

\section{Competing interests}

The authors declare that they have no competing interests.

\section{Author details}

${ }^{1}$ Department of Biomedical Engineering, National Cheng Kung University, Tainan, Taiwan. ${ }^{2}$ Department of Orthopedics, National Cheng Kung University Hospital, Tainan, Taiwan. ${ }^{3}$ Departments of Orthopaedic Surgery and Pathology, E-Da Hospital, I-Shou University, Yen-Chao District, Kaohsiung, Taiwan. ${ }^{4} \mathrm{GEG}$ Orthopedic Clinic, Tainan, Taiwan.

Received: 13 April 2021 Accepted: 21 October 2021

Published online: 28 October 2021

\section{References}

1. Ganestam A, Kallemose T, Troelsen A, Barfod KW: Increasing incidence of acute Achilles tendon rupture and a noticeable decline in surgical treatment from 1994 To 2013. A nationwide registry study of 33,160 patients. Knee Surg Sports Traumatol Arthrosc 2016, 24(12):3730-3737.

2. Huttunen TT, Kannus P, Rolf C, Fellander-Tsai L, Mattila VM. Acute achilles tendon ruptures: incidence of injury and surgery in Sweden between 2001 and 2012. Am J Sports Med. 2014;42(10):2419-23.

3. Kujala UM, Sarna S, Kaprio J. Cumulative incidence of achilles tendon rupture and tendinopathy in male former elite athletes. Clin J Sport Med. 2005;15(3):133-5.

4. Nyyssonen T, Luthje $P$, Kroger $H$. The increasing incidence and difference in sex distribution of Achilles tendon rupture in Finland in 1987-1999. Scand J Surg. 2008;97(3):272-5.

5. Saarensilta IA, Edman G, Ackermann PW: Achilles tendon ruptures during summer show the lowest incidence, but exhibit an increased risk of rerupture. Knee Surg Sports Traumatol Arthrosc 2020.

6. Kearney RS, McGuinness KR, Achten J, Costa ML. A systematic review of early rehabilitation methods following a rupture of the Achilles tendon. Physiotherapy. 2012:98(1):24-32.

7. Palmes D, Spiegel HU, Schneider TO, Langer M, Stratmann U, Budny T, et al. Achilles tendon healing: long-term biomechanical effects of postoperative mobilization and immobilization in a new mouse model. J Orthop Res. 2002;20(5):939-46.

8. Pneumaticos SG, McGarvey WC, Mody DR, Trevino SG. The effects of early mobilization in the healing of achilles tendon repair. Foot Ankle Int. 2000;21(7):551-7.

9. Wu Y, Mu Y, Yin L, Wang Z, Liu W, Wan H. Complications in the Management of Acute Achilles Tendon Rupture: a systematic review and network Meta-analysis of 2060 patients. Am J Sports Med. 2019;47(9):2251-60.

10. Leigheb M, Guzzardi G, Pogliacomi F, Sempio L, Grassi FA. Comparison of clinical results after augmented versus direct surgical repair of acute Achilles tendon rupture. Acta Biomed. 2017;88(4S):50-5.

11. Biz C, Cerchiaro M, Belluzzi E, Bragazzi NL, De Guttry G, Ruggieri P: Long Term Clinical-Functional and Ultrasound Outcomes in Recreational Athletes after Achilles Tendon Rupture: Ma and Griffith Versus Tenolig. Medicina 2021, 57(10).

12. Clanton T, Stake IK, Bartush K, Jamieson MD. Minimally invasive Achilles repair techniques. Orthop Clin North Am. 2020;51(3):391-402.

13. McMahon SE, Smith TO, Hing CB. A meta-analysis of randomised controlled trials comparing conventional to minimally invasive approaches for repair of an Achilles tendon rupture. Foot Ankle Surg. 2011;17(4):211-7

14. Assal M, Jung M, Stern R, Rippstein P, Delmi M, Hoffmeyer P. Limited open repair of Achilles tendon ruptures: a technique with a new instrument and findings of a prospective multicenter study. J Bone Joint Surg Am. 2002;84(2):161-70

15. Carmont MR, Heaver C, Pradhan A, Mei-Dan O, Gravare Silbernagel K. Surgical repair of the ruptured Achilles tendon: the cost-effectiveness of open versus percutaneous repair. Knee Surg Sports Traumatol Arthrosc. 2013;21(6):1361-8.

16. Carmont MR, Maffulli N. Modified percutaneous repair of ruptured Achilles tendon. Knee Surg Sports Traumatol Arthrosc. 2008;16(2):199-203.

17. Cretnik A, Kosanovic M, Kosir R. Long-term results with the use of modified percutaneous repair of the ruptured Achilles tendon under 
local Anaesthesia (15-year analysis with 270 cases). J Foot Ankle Surg. 2019;58(5):828-36.

18. Cretnik A, Kosanovic M, Smrkolj V. Percutaneous versus open repair of the ruptured Achilles tendon: a comparative study. Am J Sports Med. 2005;33(9):1369-79.

19. Elton JP, Bluman EM. Limited open achilles tendon repair with modified ring forceps: technique tip. Foot Ankle Int. 2010:31(10):914-5.

20. FitzGibbons RE, Hefferon J, Hill J. Percutaneous Achilles tendon repair. Am J Sports Med. 1993:21(5):724-7.

21. Kakiuchi M. A combined open and percutaneous technique for repair of tendo Achillis. Comparison with open repair. J Bone Joint Surg Br. 1995;77(1):60-3.

22. Ko PY, Huang MT, Li CL, Su WR, Jou IM, Wu PT. Jigless knotless internal brace technique for acute Achilles tendon rupture: a case series study. J Orthop Surg Res. 2019;14(1):415.

23. Ma GW, Griffith TG. Percutaneous repair of acute closed ruptured achilles tendon: a new technique. Clin Orthop Relat Res. 1977;128:247-55.

24. O'Donnell SW, Velasco B, Whitehouse B, Kwon JY, Miller CP. Limited open Achilles tendon repair in supine position with modified ring forceps: a technique tip. Foot Ankle Spec. 2019;12(6):563-8.

25. Demetracopoulos CA, Gilbert SL, Young E, Baxter JR, Deland JT. Limitedopen Achilles tendon repair using locking sutures versus nonlocking sutures: an in vitro model. Foot Ankle Int. 2014;35(6):612-8.

26. Haji A, Sahai A, Symes A, Vyas JK. Percutaneous versus open tendo achillis repair. Foot Ankle Int. 2004;25(4):215-8.

27. Lim J, Dalal R, Waseem M. Percutaneous vs. open repair of the ruptured Achilles tendon--a prospective randomized controlled study. Foot Ankle Int. 2001;22(7):559-68.

28. Maes R, Copin G, Averous C. Is percutaneous repair of the Achilles tendon a safe technique? A study of 124 cases. Acta Orthop Belg. 2006;72(2):179-83.

29. Maffulli N, Longo UG, Maffulli GD, Khanna A, Denaro V. Achilles tendon ruptures in elite athletes. Foot Ankle Int. 2011;32(1):9-15.

30. Porter KJ, Robati S, Karia P, Portet M, Szarko M, Amin A. An anatomical and cadaveric study examining the risk of sural nerve injury in percutaneous Achilles tendon repair using the Achillon device. Foot Ankle Surg. 2014;20(2):90-3.

31. Blackmon JA, Atsas S, Clarkson MJ, Fox JN, Daney BT, Dodson SC, et al. Locating the sural nerve during calcaneal (Achilles) tendon repair with confidence: a cadaveric study with clinical applications. J Foot Ankle Surg. 2013;52(1):42-7.

32. Choi GW, Kim HJ, Lee TH, Park SH, Lee HS. Clinical comparison of the two-stranded single and four-stranded double Krackow techniques for acute Achilles tendon ruptures. Knee Surg Sports Traumatol Arthrosc. 2017;25(6):1878-83.

33. Jaakkola JI, Hutton WC, Beskin JL, Lee GP. Achilles tendon rupture repair: biomechanical comparison of the triple bundle technique versus the Krakow locking loop technique. Foot Ankle Int. 2000;21(1):14-7.

34. Krackow KA, Thomas SC, Jones LC. A new stitch for ligament-tendon fixation. Brief note. J Bone Joint Surg Am. 1986;68(5):764-6.

35. Hong CK, Lin CL, Kuan FC, Wang PH, Yeh ML, Su WR. Longer stitch interval in the Krackow stitch for tendon graft fixation leads to poorer biomechanical property. J Orthop Surg (Hong Kong). 2018;26(3):2309499018799514.

36. Lee SJ, Sileo MJ, Kremenic IJ, Orishimo K, Ben-Avi S, Nicholas SJ, et al. Cyclic loading of 3 Achilles tendon repairs simulating early postoperative forces. Am J Sports Med. 2009;37(4):786-90.

37. Akizuki KH, Gartman EJ, Nisonson B, Ben-Avi S, McHugh MP. The relative stress on the Achilles tendon during ambulation in an ankle immobiliser: implications for rehabilitation after Achilles tendon repair. Br J Sports Med. 2001;35(5):329-33 discussion 333-324.
38. Orishimo KF, Burstein G, Mullaney MJ, Kremenic IJ, Nesse M, McHugh MP, et al. Effect of knee flexion angle on Achilles tendon force and ankle joint plantarflexion moment during passive dorsiflexion. J Foot Ankle Surg. 2008;47(1):34-9.

39. Heitman DE, Ng K, Crivello KM, Gallina J. Biomechanical comparison of the Achillon tendon repair system and the Krackow locking loop technique. Foot Ankle Int. 2011;32(9):879-87.

40. Huffard B, O'Loughlin PF, Wright T, Deland J, Kennedy JG. Achilles tendon repair: Achillon system vs. Krackow suture: an anatomic in vitro biomechanical study. Clin Biomech (Bristol, Avon). 2008;23(9):1158-64.

41. Labib SA, Rolf R, Dacus R, Hutton WC. The "Giftbox" repair of the Achilles tendon: a modification of the Krackow technique. Foot Ankle Int. 2009:30(5):410-4

42. Shepard ME, Lindsey DP, Chou LB. Biomechanical testing of epitenon suture strength in Achilles tendon repairs. Foot Ankle Int 2007;28(10):1074-7.

43. Watson TW, Jurist KA, Yang KH, Shen KL. The strength of Achilles tendon repair: an in vitro study of the biomechanical behavior in human cadaver tendons. Foot Ankle Int. 1995;16(4):191-5.

44. Clanton TO, Haytmanek CT, Williams BT, Civitarese DM, Turnbull TL, Massey MB, et al. A biomechanical comparison of an open repair and 3 minimally invasive percutaneous Achilles tendon repair techniques during a simulated, progressive rehabilitation protocol. Am J Sports Med. 2015;43(8):1957-64.

45. Aufwerber S, Edman G, Gravare Silbernagel K, Ackermann PW. Changes in tendon elongation and muscle atrophy over time after Achilles tendon rupture repair: a prospective cohort study on the effects of early functional mobilization. Am J Sports Med. 2020;48(13):3296-305.

46. Diniz P, Pacheco J, Guerra-Pinto F, Pereira H, Ferreira FC, Kerkhoffs G. Achilles tendon elongation after acute rupture: is it a problem? A systematic review. Knee Surg Sports Traumatol Arthrosc. 2020;28(12):4011-30.

47. Hurmeydan OM, Demirel M, Valiyev N, Sahinkaya T, Kilicoglu OI. Relationship of postoperative Achilles tendon elongation with Plantarflexion strength following surgical repair. Foot Ankle Int. 2020;41 (2):140-6.

48. Lee SJ, Goldsmith S, Nicholas SJ, McHugh M, Kremenic I, Ben-Avi S. Optimizing Achilles tendon repair: effect of epitendinous suture augmentation on the strength of achilles tendon repairs. Foot Ankle Int. 2008:29(4):427-32.

49. Mullaney MJ, McHugh MP, Tyler TF, Nicholas SJ, Lee SJ. Weakness in end-range plantar flexion after Achilles tendon repair. Am J Sports Med. 2006;34(7):1120-5.

50. Dai W, Leng $X$, Wang J, Hu X, Ao Y. Rehabilitation regimen for non-surgical treatment of Achilles tendon rupture: a systematic review and metaanalysis of randomised controlled trials. J Sci Med Sport. 2020.

51. Lu J, Liang X, Ma Q. Early functional rehabilitation for acute Achilles tendon ruptures: an update Meta-analysis of randomized controlled trials. J Foot Ankle Surg. 2019;58(5):938-45.

52. Ostrander RV 3rd, Saper MG, Juelson TJ. A biomechanical comparison of modified Krackow and locking loop suture patterns for soft-tissue graft fixation. Arthroscopy. 2016;32(7):1384-8.

53. Cox JT, Shorten PL, Gould GC, Markert RJ, Barnett MD Jr, Laughlin RT. Knotted versus knotless suture bridge repair of the achilles tendon insertion: a biomechanical study. Am J Sports Med. 2014;42(11):2727-33.

\section{Publisher's Note}

Springer Nature remains neutral with regard to jurisdictional claims in published maps and institutional affiliations. 